\title{
Role of the Counselor with Computers
}

\author{
GARRY R. WALZ
}

The computer has the potential to affect significantly the role of the counselor. Changing counselor roles are examined in light of recent computerinnovations.

$\mathrm{T}$ he computer is an invention of unparalleled significance. In the last decade several innovations have been heralded as having the power to change how we live. Probably none, however, has the potential of the computer to affect our lives in general and education in particular.

Certainly part of the reason for the tremendous impact of the computer on education is the time of its arrival. Education is currently under attack from dissatisfied constitutencies who are demanding that students acquire a great deal more from their schooling. Postsecondary education, after a decade of emphasis on equity, is now being called upon to place greater emphasis on excellence and achievement. New strategies for educating both adolescents and adults are extending learning beyond school and college walls to a variety of self-managed educational experiences. These cries for greater excellence in education and improved student performance are occurring at a time when the costs of education are rising rapidly. The demand and the need for a quantum leap in improving education is so great that if the computer did not exist, something akin to it in potential, power, and impact would have been invented.

The computer is having a strong influence on school districts across the country, on state educational plans, and on policy pronouncements for both public and postsecondary education. The clamor for the computerization of education is becoming a din. Yet even before computers have become established in the educational enterprise, some people are decrying both their potential and the way they are being used. Are computers merely "electronic page-turners," or do they have the capacity to affect significantly how students and adults learn? Will school systems, training institutions, and organizations be able to use them to change and enhance the learning process? These questions are paramount. The difficulty in answering them is compounded by the fact that the real development and contribution of computers is only now emerging. The "computational powers equivalent to that of present-day super computers ... will be available in a micro-process system for under $\$ 100$ by 1990" (Computers in Education, 1983). Clearly, any discussion about the role of the counselor with computers needs to focus not on present activities or past experience but on possible and probable developments for computers and their impact and influence on counseling and human services in the near future.

\section{CHARACTERISTICS OF COMPUTERS AND TECHNOLOGY}

There is an understandable tendency today to deal in simplistic generalizations about the computer's super powers and how it will revolutionize all that it touches, with little discussion of the concepts basic to the constructive use of computers. A discussion of computers that focuses on hardware alone overlooks the fundamental power of the computer. This is especially true in counseling, where the applications of the computer are still miniscule compared with the needs and opportunities.
Four characteristics of computers and technology will have significant effect on their adoption and use. First discussed by Walz (1970) in a Personnel and Guidance Journal special issue on technology and guidance, these characteristics have proven to be important in considering possible roles for computers in counseling and human services: (a) generation of both positive and negative outcomes; (b) increased visibility of conflict between choices and values; (c) the duality of depersonalization and individualization; and (d) influence of the social setting.

\section{Generation of Both Positive and Negative Outcomes}

Computers will create new opportunities to counsel differently and better and to perform counseling functions that have not been feasible in the past. But while the computer makes possible the achievement of new goals, some loss in the achievement of older goals may occur (e.g., greater opportunity to examine pertinent information may result in less one-to-one counselor interaction). The same technology and process will bring about both the gain and the loss.

Thus, the positive attributes of using computers must be weighed against the negative. In this process it is likely that different people will apply different criteria as to what is desirable or undesirable. Counselors with a strong interpersonal relationship orientation may have a different view than those with a guidance curriculum or a learning orientation. The fact is that even a very sophisticated technological innovation such as the computer has negative aspects. This explains why computers engender so much fear and resistance on the part of some counselors and in some educational settings.

Increased Visibility of Conflicts Between Choices and Values Using computers in counseling forces program developers to delineate clearly their values and goals. In this process people may recognize greater conflicts than were apparent when goals or means were not sharply defined. In traditional counseling settings individual counselors have operated independently, and conflicts, if they existed, could be ignored or allowed to exist without much attention or fuss. The introduction of computers into a counseling program dramatizes the need to make hard decisions about values and outcomes. Although some may bemoan the conflict associated with computers and technologies and long for the days when counselors could "do their own thing" without the necessity for such choices, the very discussion necessary for the appropriate use of computers can sharpen the programmatic focus to a degree that strengthens the entire guidance program.

The Duality of Depersonalization and Individualization In the year of Orwell's 1984 we are all sensitized to technology's potential to become the master rather than the servant. The very thought of such mechanistic processes entering the highest realm of humanistic interactions (i.e., counseling and education) convinces many that the survival of the individual as an existential being is possible only by opposing the adoption and use of computers.

The fact that 1984 is upon us and that few of the doomsday outcomes horrifyingly described by Orwell have occurred speaks 
to the ability of human beings to mediate and control the use of technology to serve their best interests. Furthermore, there is increasing evidence that in our complex world only technology can preserve and make possible the freedom and rights of humankind that we cherish so dearly. The storage and memory capacity of the. computer provides the means to respond to people as individuals. When large numbers are involved, only the grossest identification and response is possible by any means other than the computer. Many who have experienced computer-assisted counseling feel that it was an extremely "personal" experience because the interaction with the computer was so focused on them.

\section{The Influence of the Social Setting}

The social setting for the computer has a strong influence on whether or not, to what extent, and in what ways the benefits of the computer will be realized. It is undesirable, even dangerous, to either discuss the usefulness of a computer without reference to the setting in which it is to be used or generalize about the usefulness of computers from one setting to another. An adult counseling center committed to providing accurate information about career oportunities and choices is likely to use a computer very differently than a secondary school guidance program concerned with helping adolescents deal with important life plans and decisions. The computer, as a component in a highly variable social setting, is ungeneralizable because it both shapes and is shaped by the particular program in which it is used, the school or agency where it is located, or the larger community. However primitive our knowledge about computer-assisted counseling, our knowledge about how to adopt and implement computer-assisted counseling in different counseling and human services programs is even more primitive. Generalizations across different levels and settings are of little real value.

\section{NEW AND EMERGING COUNSELOR ROLES IN USING COMPUTERS}

\section{Systematic Exploration and Use of Computers}

No role for counselors in using computers is easily generalizable or clear-cut. The level, the setting, and the particular program culture will determine how the computer can be used most effectively and what outcomes will accrue. Therefore, an essential first step for counselors in defining their role will be practical experience with a variety of strategies and procedures. There is no substitute for counselor familiarity and comfort with computers. The difficulties of acquiring such experience probably have been greatly overstated. Short courses offered by computer vendors or a variety of educational institutions can provide a relatively quick, basic understanding and skill level.

Counselors can begin immediately to explore possible computer applications and use in two areas. The first, computermanaged counseling (CMC), assists counselors with the clerical and administrative tasks associated with their work, tasks that frequently inhibit their ability to undertake meaningful counselor interactions (Bleuer \& Walz, 1983). Practical applications of computer-managed counseling include the following: clientstudent recordkeeping, counseling activity logs, student and client attendance records for both individuals and groups, scheduling of individuals and groups, records of grades for easy production of transcripts, resource files for the counselor's personal use, and general word processing (e.g., report writing and personalized letters). In these areas the computer can alleviate some of the tedium and monotony of present counseling duties and allow time for more meaningful counselor-client interactions. Many existing software programs enable counselors to perform all of these tasks without great skill or expense.

A second area of exploration for counselors is computer-as- sisted counseling (CAC), which is to counseling what computerassisted instruction (CAI) is to teaching. This is an interactive counseling technique in which the computer is used to present information, elicit and monitor responses, and select and present additional information in accordance with individual client needs (Bleuer \& Walz, 1983). CAC offers three significant contributions to the counseling process: objectivity, availability, and the capacity to store and retrieve a great deal of information. Objectivity is an important aspect of any educational decision and planning relationship, and the computer is certainly objective. Availability, or the opportunity for ready access to information, is also a decided contribution of CAC. After initial instruction, clients can often use the computer with sufficient reward that additional direct interaction with a counselor is un'necessary; in other cases, clients are better prepared to have meaningful discussions with the counselor about their decisions and plans. Perhaps the greatest contribution of present-day CAC is the computer's capacity to store and retrieve many kinds of information. This ability is evident in computer software that provides career and educational information, skill-building in such areas as problem solving and decision making, interest and ability assessment through computerized testing modules, and test practice and preparation such as for the SAT.

Exploring and trying out CMC and CAC will help counselors discover ways to reduce the time they devote to repetitive, monotonous tasks that the computer can perform better. Providing clients with some-of the same meaningful experiences and learnings by computer that are possible in one-to-one counseling may also lead to improved quality for one-to-one counseling interactions.

\section{An Active Stance for Quality Assurance}

Many are inclined to judge the quality of a computer program by the complexity and quantity of the hardware. Simply stated, some people believe that the more computers are used, the more advanced and sophisticated the program. In fact, program effectiveness is more a function of quality and appropriateness of the software than of expense, or quantity of computers. The available software for counseling and guidance can be used on relatively few computers. Therefore, the first consideration in selecting a computer is to make sure that it is compatible with software that meets the needs and interests of a particular clientele. It is just as important to make sure that the chosen software is of high quality. A vital counselor role, then, is a quality assurance review of all software to be used. This is particularly important for two reasons. First, unlike print media, software programs cannot be reviewed quickly or casually. The assumptions and values inherent in the construction of each program are not readily apparent and require careful analysis. Second, unlike many guidance procedures, computer software frequently will be used by students or adults without further reference to the counselor. Such independent access makes the need for careful scrutiny all the more important. This is a responsibility that counselors cannot delegate and must carry out if computers are going to make a truly viable contribution to counseling.

\section{Evaluation of the Use of Computers}

The effects of computers in counseling processes are only beginning to be known. Although there is an emerging consensus among researchers about the positive benefits of computer-assisted counseling, the actual contribution of computers to counseling must be determined separately in each program.

Perhaps the greatest deterrent to systematic and ongoing evaluation of counseling and human services innovations has been uncertainty about how to do it. Consequently, many initially attractive innovations have been abandoned because their value could not be sufficiently substantiated to justify the added effort 
or expense. Computers, however, can compile the data needed to evaluate the quality of their services.

Counselors must be committed to gathering specific data about what computers do or do not do to achieve significant outcomes. One approach, SHAPE-Self Help Approach to Program Evaluation (Collet, Walz, \& Collet, 1983), presents a readily usable method for program self-evaluation and suggests a variety of sources for judging the value of using computers in counseling processes. This program provides a systematic approach to evaluation that does not require external consultants or complex statistical procedures. The inevitable pendulum swing will bring about questioning of the use and worth of technology in education and counseling. If counselors fail to evaluate their programs, it is likely that others will do it for them, and most likely from a nonobjective and possibly hostile perspective.

\section{Computers as an Indiscriminate Discriminator: A \\ Commitment to Equity}

Client response to computers is varied and not universally positive. Based on previous experiences, clients may approach computers with either trepidation or pleasure. Women and minority group members may show less interest or desire to use computers than do White males. Clients with linear cognitive styles may find the computer less appealing than do those with inferential thinking and learning styles. Previous experience with computer games can also influence people's response to computers.

Special efforts to minimize anxieties and to clarify false assumptions about computers could be necessary if many clients are to benefit from using them. Most users do enjoy the computerized components of a counseling experience, finding reinforcement and reward. It is a major responsibility of counselors to attend to initial attitudinal and experiential differences and to ensure that they do not keep certain individuals or groups from profiting from the counseling process.

\section{A Systematic Adoption and Implementation Process}

Ask a group of counselors how they first introduced computers into their program and you will receive as many descriptions as there are counselors. Patterns range from imposition from higher administrative authority to a strong counselor initiative to broaden the resources available within the guidance program. Evident in many of the adoption procedures used, however, is the lack of an orderly and systematic process. More often than not, decisions about installation and implementation are based on availability of funds or administrators' desires to computerize the program. The resultant patchwork quilt of usage is not conducive to realizing the full potential of computers in counseling.

A seven-step model for developing and implementing a hightech counseling program has been described by Bleuer and Walz (1983). This model emphasizes the need for customizing the computer to the particular goals and needs of a given human services program and provides a step-by-step process for counselors to follow. The steps in the model are: (a) analyze the program for potential computer applications; (b) investigate available computer resources; (c) select computer uses that will meet program needs; (d) match software to program needs; (e) match hardware to software; (f) invest in personware; and (g) implement and evaluate. Basic to this model is purposeful and planful adoption rather than an impulsive, thoughtless approach that rushes to the end state (the purchase and installation of computers) before the necessary groundwork has taken place.

The counselor should encourage excited interest in the adoption process, but should also make sure that the necessary thinking and planning occur before decisions are made or actions are taken that might later hinder or negatively affect the program. The computer has the potential for providing great individuation and flexibility within the counseling program. Unwise decisions, however, may lock the counseling staff into either behaviors or resources that actually negate their ability to respond flexibly and that could result in a more rigid program than if they had not attempted to use computers and technology at all. This is a time when counselors must stand firm and insist on careful planning and judicious implementation.

\section{Exploration into New Uses of the Computer}

Computers can help counselors accomplish old tasks in new ways or undertake new functions not previously thought of because the necessary methodology was lacking. Unfortunately, the tendency exists to try to mold this new innovation, the computer, to existing modes of thinking and behaving. Thus, in some cases computers are used primarily as efficient storage banks that offer an advantage over traditional methods of filing and retrieving information. Admittedly, this is a useful role. But counselors need to explore exciting new uses for computers in counseling.

Listed below are a few of the avenues by which counselors may use computers to enhance the scope of counseling and the quality of counseling outcomes (Computers in Education, 1983):

Tutoring. The computer can be an excellent tutor in different aspects of career and life decision making and problem solving. It is patient and can readily adapt to a variety of individual differences and needs.

Diagnosis. Computers can help to diagnose individual students' knowledge and cognitive style. Counselors can use this information to plan more, appropriate learning strategies that build on the strengths and weaknesses of a given student.

Game technologies. Computer games can provide motivation and interest for extensive practice in the problem-solving abilities associated with making major life plans and decisions. They also can serve a diagnostic function, helping to determine where individuals need additional help and practice in planning and decision making. It is possible to develop games that resemble exploratory learning environments, enabling the user to simulate deciding and behaving in actual life situations.

Networks. Through the use of telecommunications or special computer programs, it is possible to create communities or networks of participants regardless of physical location. Students interested in exploring a particular career, for example, could develop a support network using computer telecommunications. They could then interact with students in other classes or in other schools without any need for physical meetings or travel. Resources developed during the day could be shared with parents in the evening, providing an opportunity for parent-child interactions currently missing in many families.

The above are just a few of the many possibilities for using computers in counseling. Counselors must provide a creative impetus for the use of computers. They must be unwilling to accept their being able to perform old tasks better as the major or sole contribution that computers can make to counseling.

\section{COUNSELOR ROLE PRIORITIES}

The computer has the potential to affect significantly the role of the counselor. But it is only a potential. The addition of computers to a human services program does not guarantee 'that the program will be either more efficient or more effective. Rather, it is the clear identification of outcomes and the means selected for reaching those outcomes that will determine whether or not a computer will enhance the counselor role. Several considerations are paramount in redefining the counselor's role vis-àvis the computer.

1. In light of the enormous potential of the computer, we must look to the creative redesign of counseling. There is a real danger that we will automate the status quo-settling for doing what we do with a little more pizzazz and in a labor-saving mode, but with little significant change in how we define our 
role or interact with clients. Physical scientists have used computer programs as a way of testing the soundness of their theories. We need to use computers to assess the soundness of our counseling strategies and to determine how we may better achieve our goals, using the computer.

2. We must define our developmental efforts as a joint enterprise. Perhaps one of the most exciting aspects of using the computer in counseling is the opportunity it provides for individuals to work together as a team-clients, counselors, parents, and community members-to design programs that best meet individual and joint needs. In most of the areas in which counselors work, significant others play a vital role in the movement from idea to action. Making those significant others an integral part of the learning environment is fascinating and potentially beneficial. Joint planning concerning the ways computers can be used to reach a variety of counseling objectives is likely to whet the interest of these various groups regarding computer use and help to ensure that objectives are met.

3. Many aspects of the use of computers in counseling create uncertainty. Is there a synergism that will encourage students to become involved in other learning experiences, computer or otherwise? Will the increased use of computers by students disturb parents? Will extensive use of computers enhance the counselor role and encourage new, higher-level personal interactions, or will counselors become mere functionaries in an automated system? What effects will computers have on the motivation of students and adults? Will they be encouraged to seek other learning experiences and more computer interaction, or will they be less inclined to seek out new learning challenges? We need to address questions such as these as we consider broad-term effects of computers on clients. Vital to the new counselor role is a willingness to observe, identify, and assess behaviors associated with computers, on the part of both those who use them and those who provide them. This must become an important subject of discussion and analysis as we move toward a computer-enhanced counselor role.

4. Emerging research in cognitive science tells us that dialogue is a particularly meaningful way for students to learn, especially when it is followed by regular practice. This suggests a learning model not unlike typical counseling interactions and may mean that subject-oriented educational programs will be moving closer to the style of the counselor. This is an exciting opportunity for counselors to influence educational processes, leading toward discovery learning and individual planning and decision making. The computer may be the instrument for breaking down the massive walls of isolation erected by counselors over the years, prohibiting or limiting their interaction with other educators and the community. The computer can be the means for achieving coalescence. Counselors may be in a position to expand their influence in areas far wider than the traditional counseling realm.

Counseling today is still relatively untouched by technology. Although tape and video recorders and programmed instruction are a regular part of most counselor preparation programs, they are hardly ever used in day-to-day counseling. The computer, however, offers a new vision for counselors-the opportunity not only to do better what they now do but to redefine what counseling is and how it is delivered. The ultimate effectiveness of tomorrow's counselors will depend somewhat on advances in the development of hardware and relevant software, but most of all on personware-the attitudes and feelings of counselors about the adoption of a powerful new tool. It will require their giving up some of what they have done well in order to take on new means and goals. The most important new role for counselors in the use of computers may well be a sense of creative risk-taking that encourages, stimulates, and models for clients a change in viewpoint regarding the counseling experience and how to use it.

\section{REFERENCES}

Bleuer, J.C., \& Walz, G.R. (1983). Counselors and computers. Ann Arbor: ERIC/CAPS, The University of Michigan

Collet, J.C., Walz, G.R., \& Collet, L.S. (1983). SHAPE: Self-help approach to program evaluation. Ann Arbor: ERIC/CAPS, The University of Michigan

Computers in education: Realizing the potential. (1983). Chairmen's Report of a Research Conference, Pittsburgh, Pennsylvania, November 2024, 1982. Washington, DC: Superintendent of Documents, U.S. Government Printing-Office.

Walz, G.R. (1970). Technology in guidance: A conceptual overview. Personnel and Guidance Journal, 49, 175-182.

Garry R. Walz is Director, ERIC Counseling and Personnel Services Clearinghouse and a professor of Education, College of Education, University of Michigan, Ann Arbor. 